\title{
BMJ
}

\section{Cost effectiveness of home ultraviolet B phototherapy for psoriasis: economic evaluation of a randomised controlled trial (PLUTO study)}

\begin{abstract}
Mayke B G Koek, epidemiologist, medical doctor, ${ }^{1}$ Vigfús Sigurdsson, dermatologist, ${ }^{1}$ Huib van Weelden, investigator photodermatology, ${ }^{1}$ Paul H A Steegmans, dermatologist, ${ }^{2}$ Carla A F M Bruijnzeel-Koomen, professor of dermatology/allergology, ${ }^{1}$ Erik Buskens, professor of medical technology assessment ${ }^{3,4}$
\end{abstract}

\section{ABSTRACT}

Department of Dermatology

Allergology (G02.124), University

Medical Center Utrecht,

Heidelberglaan 100, 3584

CX Utrecht, Netherlands

${ }^{2}$ Department of Dermatology, St Antonius Hospital, Koekoekslaan 1. 3435 CM Nieuwegein,

Netherlands

${ }^{3}$ Department of Epidemiology, University Medical Center Groningen, University of Groningen, Hanzeplein 1, 9713 GZ Groningen, Netherlands

${ }^{4}$ Julius Centre for Health Sciences and Primary Care, University Medical Center Utrecht, Utrecht Correspondence to: M B G Koek author@koek.com

Cite this as: BMJ 2010;340:C1490 doi:10.1136/bmi.c1490 psoriasis.
Objective To assess the costs and cost effectiveness of phototherapy with ultraviolet $B$ light provided at home compared with outpatient ultraviolet B phototherapy for

Design Cost utility, cost effectiveness, and cost minimisation analyses performed alongside a pragmatic randomised clinical trial (the PLUTO study) at the end of phototherapy (mean 17.6 weeks) and at one year after the end of phototherapy (mean 68.4 weeks).

Setting Secondary care, provided by a dermatologist in the Netherlands.

Participants 196 adults with psoriasis who were clinically eligible for narrowband (TL-01) ultraviolet B phototherapy were recruited from the dermatology departments of 14 hospitals and were followed until the end of phototherapy. From the end of phototherapy onwards, follow-up was continued for an unselected, consecutive group of 105 patients for one year after end of phototherapy.

Interventions Ultraviolet B phototherapy provided at home (intervention) and conventional outpatient ultraviolet B phototherapy (control) in a setting reflecting routine practice in the Netherlands. Both treatments used narrowband ultraviolet B lamps (TL-01).

Main outcome measures Total costs to society, quality adjusted life years (QALYS) as calculated using utilities measured by the EQ-5D questionnaire, and the number of days with a relevant treatment effect $(\geq 50 \%$ improvement of the baseline self administered psoriasis area and severity index (SAPASI)).

Results Home phototherapy is at least as effective and safe as outpatient phototherapy, therefore allowing cost minimisation analyses (simply comparing costs). The average total costs by the end of phototherapy were $€ 800$ for home treatment and $€ 752$ for outpatient treatment, showing an incremental cost per patient of $€ 48(95 \% \mathrm{Cl}$ $€-77$ to $€ 174)$. The average total costs by one year after the end of phototherapy were $€ 1272$ and $€ 1148$ respectively (difference $€ 124,95 \% \mathrm{Cl} €-155$ to $€ 403$ ). Cost utility analyses revealed that patients experienced equal health benefits-that is, a gain of 0.296 versus
0.291 QALY (home $v$ outpatient) by the end of phototherapy (difference $0.0052,-0.0244$ to 0.0348 ) and 1.153 versus 1.126 QALY by one year after the end of phototherapy (difference $0.0267,-0.024$ to 0.078 ). Incremental costs per QALY gained were $€ 9276$ and $€ 4646$ respectively, both amounts well below the normally accepted standard of $€ 20000$ per QALY. Cost effectiveness analyses indicated that the mean number of days with a relevant treatment effect was 42.4 versus 55.3 by the end of phototherapy (difference $-12.9,-23.4$ to $-2.4)$. By one year after the end of phototherapy the number of days with a relevant treatment effect were 216.5 and 210.4 respectively $(6.1,-41.1$ to 53.2$)$, yielding an incremental cost of $€ 20$ per additional day with a relevant treatment effect.

Conclusions Home ultraviolet B phototherapy for psoriasis is not more expensive than phototherapy in an outpatient setting and proved to be cost effective. As both treatments are at least equally effective and patients express a preference for home treatment, the authors conclude that home phototherapy should be the primary treatment option for patients who are eligible for phototherapy with ultraviolet B light.

Trial registration Current Controlled Trials ISRCTN83025173 and Clinicaltrials.gov NCT00150930

\section{INTRODUCTION}

Psoriasis is a chronic recurrent skin disorder that can be treated symptomatically in several ways. A highly effective treatment for psoriasis is phototherapy with ultraviolet $\mathrm{B}$ light, ${ }^{1-4}$ which is indicated when topical treatment becomes insufficient. In general, guidelines and consensus agree that ultraviolet B phototherapy is the primary treatment option after failure of topical therapies. After that, treatment with a psoralen and ultraviolet A (PUVA) or systemic drugs may be considered, finally followed by so called biological agents. ${ }^{5-7}$

Phototherapy with ultraviolet B is generally offered in an outpatient clinic, requiring patients to travel to the outpatient department during working hours two or three times a week. This makes it a relatively time consuming treatment for both patients and hospital 
staff, imposing a substantial burden on patients and, presumably, on society. Another drawback may be the limited availability of outpatient phototherapy units in sparsely populated areas. As a result, patients living far from an outpatient phototherapy unit may often receive new and expensive biological treatments just because the infrastructure to deliver a well established and cheaper ultraviolet B phototherapy is lacking. ${ }^{8}$

To overcome the drawbacks of phototherapy in the outpatient clinic, equipment for use at home was introduced in the late 1970 s. $^{9-12}$ Ever since, however, the safety, effectiveness, and costs of home phototherapy have been a subject of debate because of the lack of (randomised) clinical research on the topic. In general, alleged inferior quality, higher risks, and more $\operatorname{costs}^{11-19}$ have resulted in few dermatologists embracing home phototherapy.

Recently we provided evidence that home ultraviolet $\mathrm{B}$ treatment for psoriasis is at least equally safe and effective as the conventional outpatient phototherapy. ${ }^{20} \mathrm{We}$ also showed that home phototherapy is associated with a lower burden of treatment and is better appreciated by patients than outpatient phototherapy. ${ }^{20}$ To date, a factual cost effectiveness analysis balancing the costs and effects of either treatment is still lacking. The results of such a cost effectiveness analysis would be of importance especially for policymakers and health care insurers. Since effectiveness and safety of home phototherapy are not inferior to those of outpatient phototherapy, the costs of the two treatments become more important in determining the treatment of choice. Also, in countries where home phototherapy is unavailable, the results of a cost effectiveness analysis may aid in the decision to implement this service.

We therefore carried out an economic evaluation alongside a randomised controlled trial to investigate the costs, cost effectiveness, and cost utility of home based ultraviolet $\mathrm{B}$ phototherapy for adults with psoriasis compared with conventional outpatient ultraviolet B phototherapy. The study was performed in a setting reflecting routine daily practice in the Netherlands. We used the societal perspective, and the focus was on narrowband ultraviolet $B$ treatment for psoriasis (TL-01 lamps). The Dutch acronym for this trial is PLUTO. ${ }^{21}$ The clinical results of the trial have been published previously. ${ }^{20}$

\section{METHODS}

\section{Randomised controlled trial}

Full details of the study design and interventions have been described in our paper presenting the clinical results of the PLUTO trial, ${ }^{20}$ in the study protocol (open access on www.biomedcentral.com/content/ pdf/1471-2288-6-39.pdf), ${ }^{21}$ and in the web extra on bmj.com.

The trial was a pragmatic, multicentre, single blinded, randomised clinical trial. Consenting patients $\geq 18$ years old with psoriasis who were considered clinically eligible for narrowband (TL-01) ultraviolet B phototherapy were included and randomised to receive this treatment either at home or in the outpatient department. ${ }^{2021}$ In accordance with the pragmatic design, patient selection and administration of the interventions in our trial reflected routine practice. As such, patients randomised to outpatient phototherapy received treatment in their local hospital and were treated two or three times a week. Patients randomised to receive home phototherapy were temporarily (for the duration of the phototherapy) provided with a TL-01 home phototherapy unit (Waldmann 100, Waldmann, Villingen-Schwenningen, Germany) in their homes. The unit was rented out by home care organisations (independent suppliers of medical equipment, inclusive of support from specialist nurses), who also delivered the units at the patients' homes. Irradiation took place three to four times a week (every other day), sometimes starting with daily irradiations. In both treatment arms the irradiation schedules were the schedules normally used by the hospitals and home care organisations. Neither equipment nor schedules were modified for the trial. To avoid interfering with routine practice, adjuvant use of topical therapy was allowed as well as all treatment changes initiated after inclusion and randomisation.

The within-trial economic evaluation was undertaken from the societal perspective. It focused on costs and effects at the end of phototherapy (mean duration 17.6 weeks), although results at 12 months after the end of phototherapy are also reported (mean duration 68.4 weeks). At both points in time the two treatments were compared for their total costs (cost minimisation analysis, CMA). In addition, a cost utility analysis (CUA) and cost effectiveness analysis (CEA) were performed: both groups were analysed for their differences in total costs compared with differences in quality adjusted life years (QALYs) (cost utility), and with differences in the number of days with a relevant treatment effect (cost effectiveness). QALYs were calculated from the EQ-5D quality of life questionnaire, and a relevant treatment effect was defined as a $\geq 50 \%$ improvement in the baseline psoriasis severity as measured with the self administered psoriasis area and severity index.

Fig 1 schematically represents the planned measurements. The first four measurements $(\mathrm{t}=0$ to $\mathrm{t}=3$ ) were planned according to individual clinical landmarksthat is, coinciding with inclusion in the study, start of phototherapy, around the 23rd irradiation, and at the end of phototherapy. When treatments exceeded 46 irradiations we defined 46 irradiations as the end of phototherapy. For the clinical study, all 196 participants were followed until the end of phototherapy. For the economic evaluation, however, a sample of 100 participants was deemed sufficient. As such, from the end of phototherapy onwards ( $t=4$ to $t=9$ ) an unselected group of (the first) 105 consecutive participants was followed bimonthly for one year. Therefore, analyses at 12 months after the end of phototherapy are based on data of 105 participants. 


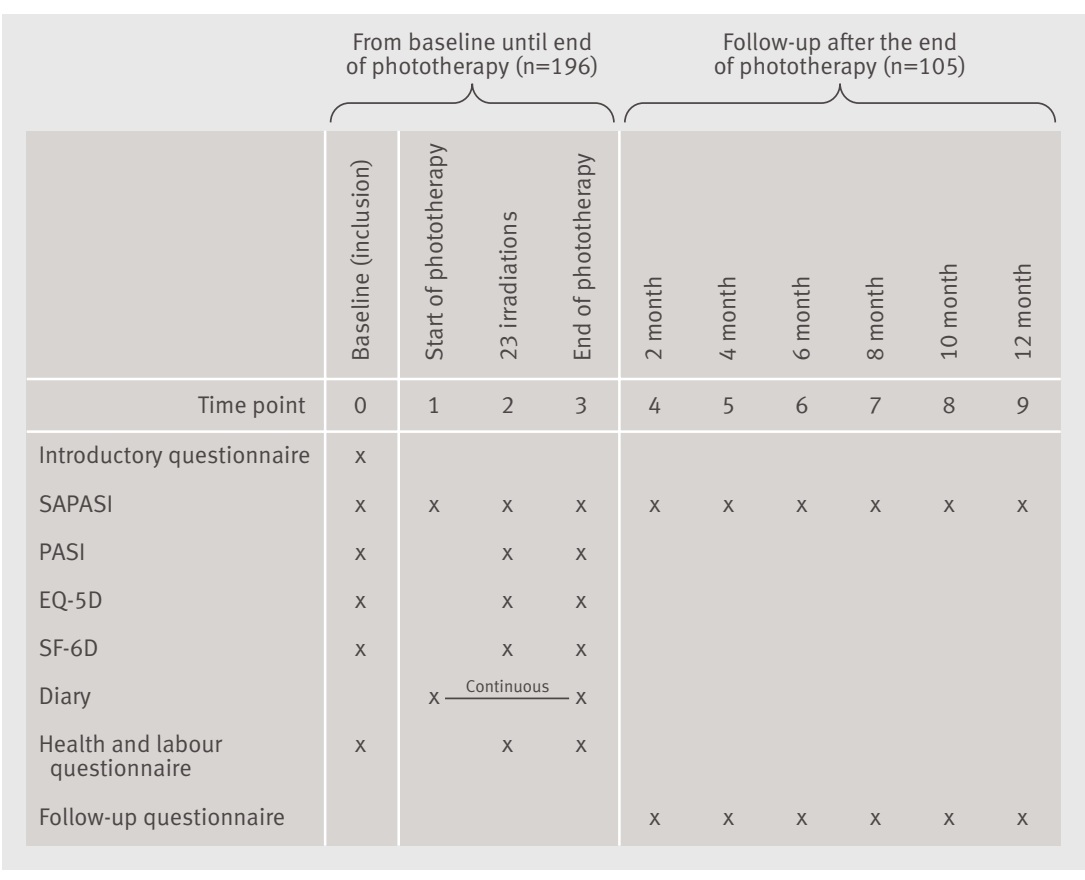

Fig 1 | Schematic representation of planned measurements of patients with psoriasis treated with ultraviolet $B$ phototherapy. PASI=psoriasis area and severity index; SAPASI=self administered PASI; EQ-5D=EuroQol questionnaire of health and quality of life outcomes; SF-6D=scoring algorithm from a subset of questions in the SF- 36 health questionnaire; diary=patients' diary of frequency and duration of irradiations and frequency of visits to dermatologist or general practitioner
Euros $(€)$ and based them on the 2003 price level or adjusted them accordingly using national indices. ${ }^{24}$

As stated above, the treatment costs of home phototherapy were not calculated from a societal perspective -because the home care organisations were reluctant to submit commercially sensitive information on pricing. As a result, we had to base the treatment costs of home phototherapy on the invoice tariffs of the two home care organisations (presented in web extra on bmj.com). It should be noted that the invoice tariffs may be higher than the true societal costs of home phototherapy. Unit costs of ultraviolet B phototherapy in an outpatient department (costs per irradiation) were calculated from the societal perpective and included the costs of staff, equipment, maintenance, depreciation, accommodation, and overheads (see web extra). Differences in treatment costs between general hospitals and university hospitals were accounted for by calculating weighted mean costs per irradiation based on the number of irradiations in both types of hospitals.

Consultation costs of dermatologists were based on the manual for costing. ${ }^{23}$ Also here, differences in costs between general hospitals and university hospitals were accounted for by calculating weighted mean costs per consultation based on the number of consultations in both type of hospitals.

Consultation costs for general practitioners were the costs presented in the manual for costing. ${ }^{23}$ Costs of concomitant drugs were determined from trial data using the prices in the Dutch medication guide $2003,{ }^{25}$ and to these we added a pharmacist's fee of $€ 6.30 .^{26}$ Travel costs were calculated from travel distances at a price of $€ 0.16$ per $\mathrm{km}$. Parking costs were $€ 2.50$ per visit to outpatient departments ${ }^{23}$ and $€ 0.25$ per visit to general practices (the latter estimated from trial data).

We planned to calculate all costs of lost productivity (absence from work and reduced productivity while at work) by applying mean hourly productivity costs varying with age and sex. ${ }^{23}$ The data obtained with the health and labour questionnaire, ${ }^{22}$ however, seemed unrepresentative of absence due to phototherapy for psoriasis. Moreover, additional trial data and previous studies led us to conclude that short term absence is often compensated for during normal working hours. ${ }^{2728}$ We therefore considered the costs due to short term absence from paid and unpaid work to be negligible (for further explanation, see web extra). To calculate productivity costs from lost productivity while at work, we used an elasticity of 0.8 , meaning a loss of 10 hours at work causes only 8 hours of productivity losses. ${ }^{23}$

Up to the end of phototherapy ( $t=3$ ), complete cost data were available for $88 \%(173 / 196)$ of the participants. Missing values were imputed with the group mean for that particular cost item.

Up to one year follow-up after the end of phototherapy $(\mathrm{t}=9)$, complete data on costs of treatment, consultations, medication, travelling, and parking were available for $88-100 \%$ (92-105) of the 105 participants. Missing values were imputed with the group mean for therapy, all costs were assessed from the spective and were calculated per patient by multiplying the volume of resource use by the unit costs. Using the manual for costing of the Dutch healthcare insurance board (CVZ) ${ }^{23}$ we assessed all costs in 
Table 1 |Use of resources by patients with psoriasis treated with ultraviolet B phototherapy and their unit costs (€)

\begin{tabular}{|c|c|c|}
\hline Resource & Unit cost $(€)$ & Source \\
\hline Home phototherapy & By individual patient & $\begin{array}{l}\text { Invoice prices home care organisations } \\
\text { (see web extra on bmj.com) }\end{array}$ \\
\hline Outpatient phototherapy (per irradiation) & $9.13^{\star}$ & Hospital data (see web extra) \\
\hline Consultation with dermatologist (10 minutes) & $57.50^{\star}$ & Manual for costing ${ }^{23}$ \\
\hline Consultation with general practitioner & 20.20 & Manual for costing ${ }^{23}$ \\
\hline Medication & By individual drug & Medication guide $2003^{25}$ \\
\hline Travelling costs (per km) & 0.16 & Manual for costing ${ }^{23}$ \\
\hline Parking costs for visits to hospital (per visit) & 2.50 & Manual for costing ${ }^{23}$ \\
\hline Parking costs for visits to general practice (per visit) & 0.25 & Reported directly (trial data) \\
\hline Absence from paid work (per hour) & 0 & NA \\
\hline Reduced productivity while at paid work (per hour) & By individual patient† & Manual for costing ${ }^{23}$ \\
\hline Absence from unpaid work (per hour) & 0 & NA \\
\hline \multicolumn{3}{|l|}{ For scenario analyses } \\
\hline $\begin{array}{l}\text { Outpatient phototherapy including cost of consultations of } \\
\text { dermatologist (per year) }\end{array}$ & $1011.67 \ddagger$ & National Health Tariffs Authority ${ }^{43}$ \\
\hline Consultations with dermatologist (per year) & 190.74 & Online list tariffs ${ }^{44}$ \\
\hline Absence from or reduced productivity in paid work (per hour) & By individual patient† & Manual for costing ${ }^{23}$ \\
\hline Absence from unpaid work (per hour) & 10.00 & Going rate for informal labour in the Netherlands in 2003 \\
\hline \multicolumn{3}{|c|}{$\begin{array}{l}\text { Values presented are unit costs for phototherapy as performed with narrowband ultraviolet B light. All unit costs are based on or adjusted to the } \\
2003 \text { price level. } \\
\text { * Weighted mean price of university hospitals and general hospitals. } \\
\text { † Depending on sex and age. } \\
\text { † Weighted mean price for the participating hospitals. }\end{array}$} \\
\hline
\end{tabular}

that particular cost item. All estimates of costs of work absence and lost productivity while at work during the follow-up were based on assessments made during the treatment period.

\section{Health outcomes}

\section{Clinical effectiveness}

We determined the severity of disease with the psoriasis area and severity index (PASI) ${ }^{29}$ and the self administered PASI (SAPASI) ${ }^{30-32}$ Both scales range from 0 (no lesions) to 72 (extensive erythroderma of the severest degree). Our main outcome measure was the proportion of patients achieving a relevant treatment effect - that is, a $\geq 50 \%$ reduction in the baseline PASI or SAPASI (the so called PASI 50 and SAPASI 50). Other measures were the proportion of patients achieving a successful treatment effect $(\geq 75 \%$ reduction in baseline disease severity, SAPASI 75 or PASI 75). Treatment safety was assessed by monitoring the occurrence of acute side effects and measuring the total cumulative dose of ultraviolet B light. We also collected data on demographics, burden of treatment, patient satisfaction, and preferences.

Cost utility analyses

For the cost utility analyses, we measured health benefit in terms of quality adjusted life years (QALYs) using EQ-5D utilities. ${ }^{33}$ We calculated QALYs by plotting utilities against time, using the area under the curve approach.

As an alternative utility measure, we used SF-6D utilities calculated from the short form 36 (SF-36) questionnaire. $^{3435}$ The EQ-5D and SF-6D utility scores were measured at baseline $(\mathrm{t}=0)$, after 23 irradiations $(\mathrm{t}=2)$, and at the end of phototherapy $(\mathrm{t}=3)$ (see fig 1$)$.
For those three assessment points, complete data were available for $94 \%(185 / 196)$ of the participants.

Because of the study design, however, utility scores were missing for all participants at the start of phototherapy $(\mathrm{t}=1)$ and during follow-up $(\mathrm{t}=4$ to $\mathrm{t}=9)$. We estimated these missing scores using linear multilevel models (see web extra) and were able to estimate accurately the utility score from patients' SAPASI score, sex, and employment status using the following models:

EQ-5D $\times 100=89.843-(1.428 \times$ SAPASI $)$

-10.339 (only for women) +8.341 (only when employed)

SF-6D $\times 100=82.499-(0.976 \times$ SAPASI $)-7.939$ (only for women) +6.471 (only when employed )

- $(0.488 \times$ SAPASI) (only when employed).

If the use of multilevel models was impossible (because of unknown psoriasis severity), we imputed single missing utility scores using linear interpolation between the two known values on either side. Remaining missing data were imputed with the group mean for the same assessment point.

\section{Cost effectiveness analyses}

For the cost effectiveness analyses, we measured health benefit using an integrated measure of clinical effectiveness and time. For that purpose, we calculated the number of days that participants experienced a relevant treatment effect $(\geq 50 \%$ improvement in baseline SAPASI, SAPASI 50). The outcome was calculated using linear interpolation from the SAPASI scores and the various dates of measurement. Similarly, we assessed the number of days with a successful treatment effect $(\geq 75 \%$ improvement in baseline SAPASI, SAPASI 75). Any missing data that were needed to 
Table 2 |Use of resources during trial of ultraviolet B phototherapy for patients with psoriasis. Values are means (standard deviations)

\begin{tabular}{|c|c|c|c|c|}
\hline & \multicolumn{2}{|c|}{ End of phototherapy* } & \multicolumn{2}{|c|}{ One year after the end of phototherapy* } \\
\hline & Home therapy & Outpatient therapy & Home therapy & Outpatient therapy \\
\hline \multicolumn{5}{|l|}{ No of UV irradiations: } \\
\hline At home & $33.96(11.70)$ & $1.73(8.54)$ & $37.35(19.62)$ & $4.33(13.75)$ \\
\hline In outpatient department & $0.48(2.61)$ & $26.89(12.03)$ & $5.04(12.21)$ & $30.90(18.96)$ \\
\hline \multicolumn{5}{|l|}{ No of consultations: } \\
\hline With dermatologist & $1.19(0.99)$ & $1.60(1.16)$ & $4.12(3.20)$ & $3.93(2.39)$ \\
\hline With general practitioner & $0.25(0.80)$ & $0.13(0.43)$ & $0.72(1.59)$ & $1.00(4.08)$ \\
\hline Medication† & - & - & - & - \\
\hline Reduced productivity while at paid work (hours) & $2.09(8.16)$ & $4.80(17.83)$ & $2.67(7.19)$ & $3.39(8.68)$ \\
\hline
\end{tabular}

calculate the number of days with a relevant treatment effect versus a successful treatment effect were imputed with the group mean.

\section{Statistical analysis}

All comparisons were performed at the end of phototherapy and at one year after the end of phototherapy. It was not necessary to discount costs and outcomes, as psoriasis is a chronic recurrent disease and the beneficial effect of phototherapy with ultraviolet B light will generally not last beyond one year.

Initially, we analysed cost and health benefits separately. We calculated mean costs, mean QALYs, and mean number of days with a relevant treatment effect with their standard deviations for both treatment groups. Mean differences between both groups are presented with their 95\% confidence intervals.

After that, we combined differences in total costs with incremental health benefits: first with differences in QALYs (cost utility analyses), and then with differences in number of days with a relevant treatment effect (cost effectiveness analyses). By dividing the incremental costs by the incremental health benefits, we produced Incremental Cost Effectiveness Ratios (ICERs), yielding estimates of costs per QALY gained and costs per additional day with a relevant treatment effect.

We estimated uncertainty around the incremental cost effectiveness ratios (ICERs) using bootstrapping, generating 1000 replications of each ratio (replicated ICERs). For visual conceptualisation, we depicted these replicated ICERs in a cost effectiveness plane. Thus, the simultaneous dispersion of costs and effects could be evaluated, and an inference regarding the likelihood of one treatment being more cost effective than the other was possible. To indicate the level of uncertainty around the point estimates of cost per QALY, we used the replicated ICERs to produce cost acceptability curves. ${ }^{36}$

Eventually we examined the robustness of our results using sensitivity analyses or rather scenario analyses, presenting three scenarios. Firstly, we investigated the scenario when QALYs were calculated from the SF-6D utilities instead of the EQ-5D utilities.

Secondly, we examined the scenario in which the costs of absence from paid work were not considered negligible. For this scenario, hours of absence at paid work were estimated from the actual time spent on phototherapy, adjusted for the participant's employment status (full time equivalent). Thus, the hours of absence from paid work were estimated by multiplying the time spent on phototherapy and consultations (including travel time) with the participants' full time equivalent. Subsequently, mean hourly productivity costs varying with age and sex, and an elasticity of 0.8 were applied..$^{23}$ The costs of absence from unpaid work were valued at $€ 10$ per hour (going rate for informal labour in the Netherlands in 2003).

Finally, we examined a scenario in which the treatment costs of home phototherapy and those of hospital based phototherapy were assessed with similar methods. As described above, the treatment costs of outpatient phototherapy were calculated from the societal perspective, whereas the treatment costs of home phototherapy had to be calculated using invoice prices (payers' perspective). For this last scenario we therefore calculated the treatment costs for both interventions using invoice prices.

All data were analysed according to the intention to treat principle ${ }^{2021}$ using SPSS 15.0 and Microsoft Excel.

\section{RESULTS}

A total of 196 patients were randomised into two treatment arms of 98 participants each. Mean ages at baseline were 41.2 and 45.0 years (home versus outpatient treatment), and two thirds of each group $(67 \%, n=66)$ were men. The mean self administered psoriasis area and severity index (SAPASI) at baseline was 7.2 and 7.3 respectively. Most of the participants were employed $(74.5 \%(\mathrm{n}=73)$ and $70.4 \%(\mathrm{n}=69))$, their mean full time equivalents were 0.86 and 0.87 . Mean travel distances to hospital and general practice were $8.2 \mathrm{~km}$ and $2.2 \mathrm{~km}$ for the group assigned to home phototherapy, versus $11.5 \mathrm{~km}$ and $2.2 \mathrm{~km}$ for the 
Table 3 |Cumulative mean costs $(€)$ of ultraviolet $B$ phototherapy for patients with psoriasis during trial

\begin{tabular}{|c|c|c|c|c|c|c|}
\hline & \multicolumn{3}{|c|}{ End of phototherapy* } & \multicolumn{3}{|c|}{ One year after the end of phototherapy* } \\
\hline & $\begin{array}{l}\text { Home } \\
\text { therapy }\end{array}$ & $\begin{array}{l}\text { Outpatient } \\
\text { therapy }\end{array}$ & $\begin{array}{l}\text { Difference } \\
(95 \% \mathrm{Cl})\end{array}$ & $\begin{array}{l}\text { Home } \\
\text { therapy }\end{array}$ & $\begin{array}{l}\text { Outpatient } \\
\text { therapy }\end{array}$ & $\begin{array}{l}\text { Difference } \\
(95 \% \mathrm{Cl})\end{array}$ \\
\hline \multicolumn{7}{|l|}{ Direct medical costs } \\
\hline Phototherapy & 577 & 275 & 301 (257 to 346$)$ & 672 & 358 & $314(204$ to 424$)$ \\
\hline Consultations with dermatologist & 69 & 92 & $-23(-41$ to -6$)$ & 237 & 226 & $11(-52$ to 74$)$ \\
\hline Consultations with general practitioner & 5.0 & 2.6 & $2.4(-1.2$ to 6.1$)$ & 15 & 20 & $-6(-29$ to 18$)$ \\
\hline Medication & 77 & 95 & $-18(-53$ to 17$)$ & 228 & 261 & $-33(-168$ to 103$)$ \\
\hline Subtotal & 727 & 464 & 263 (199 to 326) & 1151 & 864 & 287 (50 to 523$)$ \\
\hline \multicolumn{7}{|l|}{ Direct non-medical costs (travel costs)† } \\
\hline For phototherapy & 2.9 & 144 & $-141(-168$ to -115$)$ & 20 & 160 & $-140(-204$ to -75$)$ \\
\hline For visits to dermatologist & 5.3 & 8.6 & $-3.3(-5.4$ to -1.1$)$ & 21 & 20 & $0.36(-9$ to 9$)$ \\
\hline For visits to general practitioner & 0.24 & 0.12 & $0.12(-0.09$ to 0.32$)$ & 0.55 & 0.41 & $0.14(-0.38$ to 0.66$)$ \\
\hline Subtotal & 8.5 & 153 & $-144(-171$ to -117$)$ & 42 & 181 & $-139(-211$ to -68$)$ \\
\hline \multicolumn{7}{|l|}{ Indirect non-medical costs } \\
\hline Absence from paid work & 0 & 0 & NA & 0 & 0 & NA \\
\hline Reduced productivity while at paid work & 65 & 135 & $-70(-180$ to 40$)$ & 80 & 103 & $-23(-123$ to 76$)$ \\
\hline Absence from unpaid work & 0 & 0 & NA & 0 & 0 & NA \\
\hline Subtotal & 65 & 135 & $-70(-180$ to 40$)$ & 80 & 103 & $-23(-123$ to 76$)$ \\
\hline Total costs & 801 & 752 & $48(-78$ to 174$)$ & 1272 & 1148 & $124(-155$ to 403$)$ \\
\hline \multicolumn{7}{|l|}{ Incremental cost effectiveness ratios (ICERs) } \\
\hline Cost per EQ-5D QALY gained & \multicolumn{3}{|c|}{ 9276/QALY } & \multicolumn{3}{|c|}{ 4646/QALY } \\
\hline Cost per SF-6D QALY gained & \multicolumn{3}{|c|}{ 7908/QALY } & \multicolumn{3}{|c|}{ 7802/QALY } \\
\hline $\begin{array}{l}\text { Costs per day gained with a relevant } \\
\text { treatment effect } \ddagger\end{array}$ & \multicolumn{3}{|c|}{ Dominated strategy } & \multicolumn{3}{|c|}{$20.50 /$ day with a relevant treatment effect } \\
\hline \multicolumn{7}{|c|}{ 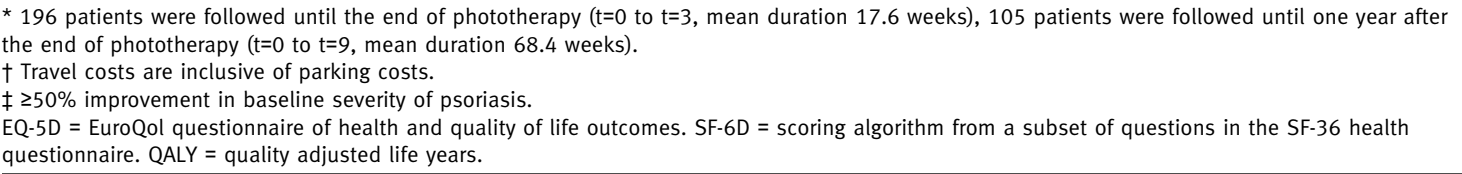 } \\
\hline
\end{tabular}

group receiving phototherapy in an outpatient department. All 196 participants were followed until the end of the phototherapy, mean duration 17.6 weeks (17.9 $v$ 17.4). The first consecutive 105 patients ( 54 home therapy, 51 outpatient therapy) continued the trial until one year after the end of phototherapy. The mean duration of the entire trial was 68.4 weeks $(68.7 v 68.1)$.

\section{Health outcomes}

\section{Clinical study}

The results of the clinical study ${ }^{20}$ indicated that home ultraviolet B phototherapy and outpatient phototherapy are at least equally safe and effective. For example, $82 \%$ of the patients treated at home and $79 \%$ of the patients treated in hospital achieved $\geq 50 \%$ improvement in baseline SAPASI (SAPASI 50) at the end of phototherapy (difference 3\%, 95\% confidence interval $-8.6 \%$ to $14.2 \%$ ), while $70 \%$ and $73 \%$ had reached the PASI 50 (difference $3 \%,-15.7 \%$ to $11.1 \%$ ). For $\geq 75 \%$ improvement in baseline score, these figures were $69 \%$ versus 59\% (SAPASI 75) (difference 10\%, $-4.0 \%$ to $23.6 \%$ ), and $41 \%$ versus $42 \%$ (PASI 75 ) (difference $-1 \%,-15.6 \%$ to $13.6 \%$ ). Safety, as assessed from the total cumulative doses of ultraviolet $\mathrm{B}$, was similar for both groups, and also the occurrence of short term side effects did not differ. ${ }^{20}$ Patients treated at home, however, had a lower burden of treatment and evaluated their therapy significantly more positively than patients treated in an outpatient department ( $\mathrm{P}$ values $\leq 0.001$ ). Waiting time (time between inclusion in trial and start of phototherapy) for home phototherapy was sometimes considerable, but 73\% (63/86) of the patients treated at home thought the waiting time was acceptable or not a problem. For the group treated in an outpatient department, this proportion was $79 \%(46 / 58) .{ }^{20}$

\section{Economic evaluation}

By the end of phototherapy ( $t=3$, mean 17.6 weeks) patients treated at home experienced 0.2960 QALYs compared with 0.2908 QALYs for patients treated in an outpatient department, indicating no significant difference in health benefit (difference $0.0052,-0.0244$ to $0.0348)$. One year after the end of phototherapy $(t=9$, mean 68.4 weeks) these figures were 1.1528 and 1.1261 respectively (difference $0.0267,-0.024$ to 0.078 ).

Health benefits in terms of number of days with a relevant treatment effect $(\geq 50 \%$ improvement) were 42.4 (home therapy) versus 55.3 (outpatient therapy) by the end of phototherapy. As such, patients treated at home experienced 12.9 fewer days with a relevant treatment effect than patients treated in an outpatient department (95\% confidence interval -23.4 to -2.4$)$. By one year after the end of phototherapy, however, this difference seemed to be reversed, point estimates 


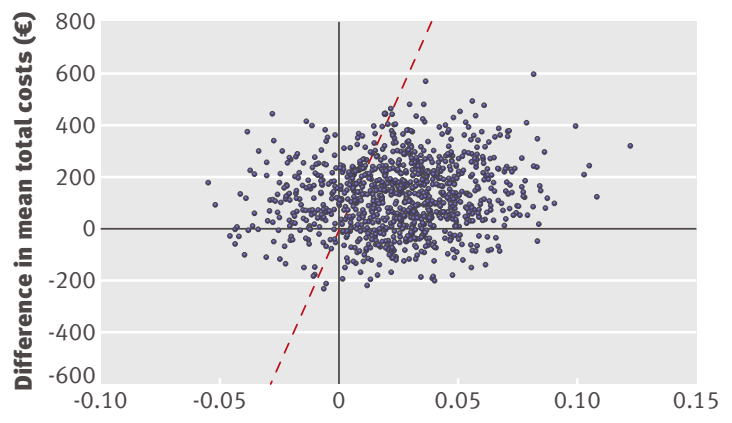

Difference in mean QALYs

Fig 2 | Incremental costs and QALYs for ultraviolet B phototherapy at home when compared with phototherapy at hospital: cost effectiveness plane for incremental costs and QALYs at one year after the end of phototherapy (entire study period, 68 weeks), with cost effectiveness threshold line (€20000/QALY)

being 216.5 days (home therapy) versus 210.4 days (outpatient therapy) with a relevant treatment effect (difference $6.1,-41.1$ to 53.2 ). The number of days with $\geq 75 \%$ improvement (successful treatment effect) were 23.0 versus 24.6 by the end of phototherapy (difference $-1.6,-9.2$ to 6.0 ) and 127.6 versus 111.1 by one year after the end of phototherapy (difference 16.5, -27.3 to 60.2 ).

\section{Costs}

Table 2 summarises the mean use of resources by the end of phototherapy $(t=3)$ and by one year thereafter $(t=9)$. From unit costs and use of resources, we calculated the direct and indirect medical and non-medical costs and combined them into mean overall costs of both interventions (see table 3).

By the end of phototherapy $(t=3)$ the overall costs were $€ 801$ for home phototherapy and $€ 752$ for outpatient phototherapy (difference $€ 48, €-78$ to $€ 174$ ). By one year after the end of phototherapy $(t=9)$ these costs had risen to $€ 1272$ and $€ 1148$ respectively (difference $€ 124, €-155$ to $€ 403)$.

\section{Cost utility analyses}

Although the point estimates presented above are not significantly different across both groups, they suggest that home phototherapy might be slightly more beneficial (gain of QALYs) but also slightly more expensive.

By the end of phototherapy $(t=3)$ the incremental cost effectiveness ratio (ICER), which relates increased total costs to a gain in QALYs, was $€ 9276$ per QALY $(€ 48.24 / 0.0052$ QALY). This indicates that each QALY gained by switching from outpatient phototherapy to home phototherapy costs $€ 9276$. By one year after the end of phototherapy $(t=9)$ the ICER was only $€ 4646$ per QALY (€124.05/0.0267 QALY). Fig 2 represents the 1000 replicated ICERs for cost per QALY at one year after the end of phototherapy $(\mathrm{t}=9)$ (generated with the bootstrapping technique), together with the cost effectiveness threshold line of $€ 20000$ per QALY. Cost acceptability (proportion of replicated ICERs on the right side of the line) was $76.3 \%$.
Fig 3 shows the cost acceptability curve at one year after the end of phototherapy ( $t=9)$, showing the level of uncertainty around the point estimates of cost per QALY. To illustrate, if policymakers are prepared to pay $€ 20000$ for each QALY gained, then they can be $76.3 \%$ sure that home ultraviolet B phototherapy is cost effective. However, if they are willing to pay $€ 10000$ or $€ 30000$ per QALY, they can be $66.7 \%$ or $79.2 \%$ sure that home phototherapy is cost effective. The results at the end of phototherapy $(t=3)$ indicated that the likelihood of home phototherapy being cost effective was $56.9 \%$ (€20 000/QALY).

\section{Cost effectiveness analyses}

For the cost effectiveness analyses, the point estimates were not significantly different between the two groups. By one year after the end of phototherapy $(\mathrm{t}=9)$, home phototherapy seemed slightly more beneficial but also slightly more expensive. The ICER relating incremental costs to differences in the number of days with a relevant treatment effect $(\geq 50 \%$ improvement) was $€ 20.50$ ( $€ 124.05 / 6.05$ days with relevant effect). This indicates that $€ 20.50$ is needed to add one day with a relevant treatment effect. Fig 4 shows the 1000 replicated ICERs for cost per additional day with a relevant treatment effect by one year after the end of phototherapy $(t=9)$.

At the end of phototherapy $(t=3)$, however, outpatient phototherapy seemed more beneficial while also saving $€ 3.73$ per day with a relevant treatment effect, indicating that outpatient therapy was the dominant strategy at this time point.

\section{Scenario analyses}

The scenario analysis addressed three areas of subjectivity, two concerning a revised calculation of costs and one concerning calculation of QALYs.

Firstly, when we assessed utilities using the SF-6D instead of the EQ-5D, the calculation of QALY gain and ICERs yielded identical results. The ICERs totalled $€ 7908$ per QALY at the end of phototherapy $(t=3)$ and $€ 7802$ per QALY at one year after the end of phototherapy ( $\mathrm{t}=9)$ (see table 3). The likelihood of home phototherapy being cost effective (cost acceptability) was $62.1 \%$ and $67.9 \%$ respectively.

Secondly, if costs had been calculated based on the revised assumptions, the total costs for society would increase for both treatment groups. The increase in costs for the group treated at home, however, would be much smaller than the increase in costs for the group randomised to receive outpatient phototherapy. As a result, for these scenarios the mean costs for home phototherapy were lower than the costs for outpatient phototherapy. Table 4 gives the results of the newly calculated costs per group. Combined with the gain in QALYs for the group treated at home, the alternative calculation of costs would produce dominated strategies.

\section{DISCUSSION}

The results of the clinical study indicated that home phototherapy with ultraviolet B for treating psoriasis 


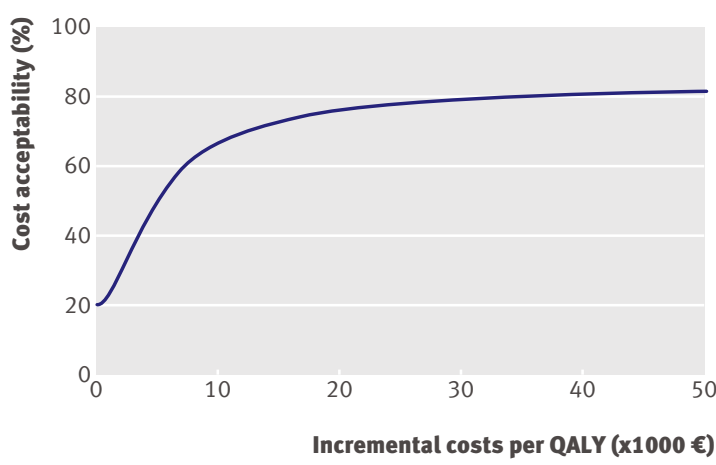

Fig 3 Cost acceptability for incremental costs per QALY for ultraviolet $B$ phototherapy at home when compared with phototherapy at hospital. Cost acceptability curve at one year after the end of phototherapy (entire study period, 68 weeks).

is at least equally effective and safe as office based phototherapy. ${ }^{20}$ In the present economic evaluation, home phototherapy seemed to be slightly more effective but also slightly more expensive than phototherapy in an outpatient department. However, both at the end of phototherapy and at one year thereafter, the differences between both treatment groups were mostly small and not significant. The incremental cost effectiveness ratios (ICERs) remained well below the generally accepted standard of $€ 20000$ per QALY. As such, home phototherapy may be regarded a cost effective intervention.

\section{Key findings}

Both at the end of phototherapy and at one year after the end of phototherapy, the total costs for home phototherapy were slightly higher than the total costs for outpatient treatment. The differences were not significant and were small ( $€ 48 / 17.6$ weeks and $€ 124 / 68.4$ weeks), especially when the lower burden of treatment and higher patient satisfaction of home phototherapy are considered. ${ }^{20}$

Just as the costs between treatments did not differ significantly, neither did the health effects as measured in QALYs. When both measures were combined, the ICERs remained far below $€ 20000$ per QALY, making home ultraviolet $B$ treatment a cost effective intervention. Calculating QALYs and ICERs using the SF-6D instead of the EQ-5D did not change these conclusions.

The use of more clinical measures of effectiveness (the number of days with a relevant or successful treatment effect) did add some interesting detail to our results. The data show that at the end of phototherapy, the patients treated in an outpatient department had experienced significantly more days with a relevant treatment effect ( $50 \%$ improvement). The difference was 13 days in favour of patients treated in an outpatient department. However, this difference was not observed for the number of days with a successful treatment effect (75\% improvement). In addition, at one year after the end of the phototherapy the difference was reversed (not significantly), indicating that patients treated at home might have a better outcome. Since the patients treated at home experienced a waiting time of 5.8 weeks on average (compared with 2.2 weeks for outpatient treatment), ${ }^{20}$ we conclude that the longer waiting time for home phototherapy in the Netherlands adversely affected the time with relevant reduction of symptoms. Obviously, in other settings the waiting time may be different. On the other hand, we found that most $(76 \%)$ of the participants thought the waiting time was not a problem or was acceptable. Also most patients in both groups $(92 \%$ of those treated at home and $60 \%$ of those treated in an outpatient department) stated they would prefer home phototherapy if they needed ultraviolet $B$ treatment again in the future, and, most important, home phototherapy was better appreciated by the patients. ${ }^{20}$ From the patient's perspective, therefore, the difference in number of days with a $50 \%$ improvement at the end of phototherapy, although significant, hardly alters the valuation of treatment. Besides, all other measures of effectiveness showed no significant differences between the groups.

In the calculation of costs, it should be noted that the home care organisations were reluctant to submit commercially sensitive information on pricing. We were therefore unable to calculate the treatment costs for home phototherapy from a societal perspective but had to use invoice prices to approximate these costs. By doing so, we have probably overestimated the costs of home phototherapy for society. It is plausible to assume that had we been able to calculate the treatment costs of home phototherapy from a societal perspective, home phototherapy might have ended up cheaper than outpatient phototherapy. To examine the effect of using invoice prices for home treatment on the overall costs, we therefore performed a scenario analysis in which we used invoice prices for outpatient based phototherapy as well. The mean invoice prices for outpatient phototherapy were much higher than the costs estimated for society, and also higher than the mean invoice prices for home phototherapy. In this scenario home phototherapy was more effective and cheaper than phototherapy in an outpatient department-that is, home therapy would be the dominant treatment strategy.

Another point to consider is that the results discussed above were calculated assuming that the costs of absence at work were negligible. By doing so, we might have underestimated the total costs of phototherapy, especially those of phototherapy in an outpatient setting. The results of the scenario analysis clearly showed that, by incorporating costs of absence at work, the costs of outpatient phototherapy would increase more than the costs of home phototherapy. This would make home phototherapy the cheaper option, again resulting in home therapy becoming the dominant treatment strategy.

\section{Comparison with other studies}

To our knowledge, this is the first clinical trial on cost effectiveness of home phototherapy compared with outpatient phototherapy for psoriasis. Also no other economic evaluations comparing home phototherapy 


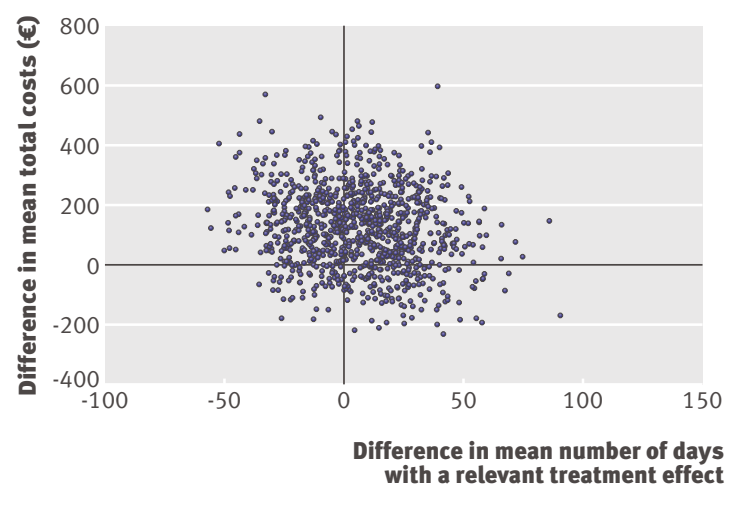

Fig 4 | Incremental costs and number of days with a relevant treatment effect ( $\geq 50 \%$ improvement from baseline) for ultraviolet B phototherapy at home when compared with phototherapy at hospital: cost effectiveness plane for incremental costs and incremental number of days with a relevant treatment effect at one year after the end of phototherapy (entire study period, 68 weeks)

with the standard outpatient phototherapy have been published, but there are some papers that touch on the subject. For instance, Yelverton et $\mathrm{al}^{37}$ reported that home phototherapy with ultraviolet B light was cost effective. They, however, compared home ultraviolet $B$ treatment with systemic treatments and with ultraviolet A combined with a psoralen (PUVA), and did not perform a cost effectiveness analysis but estimated the costs of a 30 year treatment period. Since psoriasis is a chronic disease that is generally treated by a rotation of several different therapies, calculation of the costs of a 30 year treatment period with just one therapy does not make much sense. Their results do, however, hint towards home phototherapy being cost effective for short term treatments. A study by Cameron $^{16}$ and several other papers ${ }^{38-41}$ suggest that home ultraviolet B phototherapy is likely to be more cost effective than hospital based phototherapy. A study of de Rie et al, published in $2001,{ }^{42}$ confirms the accuracy of the range of the costs we calculated for outpatient ultraviolet B phototherapy.

\section{Strengths and weaknesses of the study}

This economic evaluation benefited from being part of a pragmatic randomised clinical trial. The parallel group design meant the two interventions were compared throughout the same season, while selection bias was prevented by randomly assigning participants to the treatment arms. The pragmatic design ensured that the two treatments were applied and compared as they are used in daily practice, hence guaranteeing a good generalisability of the results. Measurement planning throughout the study took place according to individual clinical landmarks (see fig 1) and did not use fixed time points starting from baseline. This way of planning measurements was an advantage for the clinical study because it ensured that both groups could be compared at clinically comparable moments.

For the cost effectiveness study the applied planning of measurements had a drawback. Namely, the length of the waiting time and the length of the treatment period varied per patient (the latter due to differences in the number and frequency of irradiations). As a result, the time until the end of phototherapy was slightly different for the two groups (17.9 weeks for patients treated at home and 17.4 weeks for those treated in an outpatient department). Likewise, the mean total study duration (time until one year after the end of phototherapy) was slightly different for the groups (68.1 weeks and 68.7 weeks respectively). This half week difference in mean study duration might have given a small overestimation of both the incremental costs and incremental effects of home phototherapy. For the cost effectiveness analyses and cost utility analyses, however, this is likely to have negligible if any influence, because the overestimation of both values will disappear when they are combined in an incremental cost effectiveness ratio.

During the one year follow-up after the end of phototherapy ( $\mathrm{t}=4$ to $\mathrm{t}=9$ ), we deliberately did not apply certain questionnaires (see fig 1). This was in order to reduce the total number and length of the questionnaires per measurement and thereby help maintain adequate response rates. We chose not to apply questionnaires to measure health utilities (EQ-5D, SF-6D), as well as the health and labour questionnaire, theoretically making the calculation of QALYs and costs less accurate. However, we think we have estimated QALYs accurately using the multilevel linear models described in the technical appendix (web extra on bmj.com). Moreover, the uncertainty for the estimated

Table 4 | Scenario analysis of the effects of revised assumptions on mean total costs $(€)$ of ultraviolet B phototherapy for patients with psoriasis

\begin{tabular}{|c|c|c|c|c|c|c|}
\hline \multirow[b]{2}{*}{ Scenario } & \multicolumn{3}{|c|}{ End of phototherapy* } & \multicolumn{3}{|c|}{ One year after the end of phototherapy* } \\
\hline & $\begin{array}{l}\text { Home } \\
\text { therapy }\end{array}$ & $\begin{array}{c}\text { Outpatient } \\
\text { therapy }\end{array}$ & $\begin{array}{c}\text { Difference } \\
(95 \% \mathrm{Cl})\end{array}$ & $\begin{array}{l}\text { Home } \\
\text { therapy }\end{array}$ & $\begin{array}{c}\text { Outpatient } \\
\text { therapy }\end{array}$ & $\begin{array}{c}\text { Difference } \\
(95 \% \mathrm{Cl})\end{array}$ \\
\hline A. Outpatient phototherapy costs based on invoice tariffs $†$ & 838 & 1362 & $-524(-657$ to -392$)$ & 1336 & 1805 & $-469(-768$ to -169$)$ \\
\hline $\begin{array}{l}\text { B. Costs of absence at paid work estimated from time spent } \\
\text { on therapy, adjusted for employment status } \neq\end{array}$ & 1112 & 1816 & $-704(-1053$ to -356$)$ & 1857 & 2209 & $-351(-973$ to 270$)$ \\
\hline C. $A+B$ & 1149 & 2426 & $-1277(-1637$ to -917$)$ & 1921 & 2865 & $-944(-1608$ to -280$)$ \\
\hline
\end{tabular}

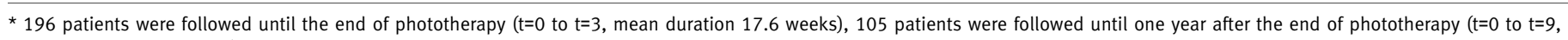
mean duration 68.4 weeks).

† Costs of outpatient phototherapy were based on invoice tariffs rather than based on the real costs for society.

$\ddagger$ Hours of absence from paid work estimated from actual time spent on therapy (including time for travelling and consultations), adjusted for employment status (that is, full time equivalent). Hourly productivity costs varying with age and sex were applied. ${ }^{23}$ Costs of absence from unpaid work valued at $€ 10$ per hour. 


\section{WHAT IS ALREADY KNOWN ON THIS TOPIC}

Ultraviolet B phototherapy for psoriasis is mostly performed in outpatient departments, making it time consuming and potentially costly

A recent study showed that ultraviolet B phototherapy provided in patients' homes is at least equally effective and safe as outpatient phototherapy, but the burden of treatment is lower and patients preferred home treatment

\section{WHAT THIS STUDY ADDS}

Ultraviolet B phototherapy at home is not more expensive than phototherapy in an outpatient setting and is a cost effective alternative to outpatient based phototherapy

In countries where home phototherapy is not common practice, implementation of this practice should be investigated. In countries where home phototherapy is available, provision should be improved and home phototherapy should be routinely reimbursed.

costs during the one year follow-up mainly concerns the productivity costs (due to absence from work or reduced productivity at work). Our data, however, indicated that most patients compensated for their short term absence during normal working hours. Also a pilot study among 36 patients confirmed that most patients can minimise costs of productivity losses by means of flexible arrangements with their employers. As such, we considered productivity losses to be of minor importance in determining the total costs for both treatment arms.

Despite the mentioned limitations, we feel that the results of our study are unambiguous. Even more, we think that the results of this study are relevant not only for patients with psoriasis but for all patients who may benefit from phototherapy with ultraviolet B light, such as those with eczema or vitiligo. After all, the results show that ultraviolet $B$ treatment can just as well be given at home instead of in an outpatient department.

\section{Implications for practice and policy makers}

Despite the fact the Netherlands is a densely populated country and distances to the hospital are relatively small, the results of this economic evaluation unequivocally indicate that home ultraviolet $B$ phototherapy is a cost effective treatment. Total costs to society for home phototherapy were similar to those of phototherapy in outpatient departments, as were the overall effectiveness and safety of home phototherapy. Considering the lower burden of treatment and patients' greater satisfaction with and preference for home phototherapy, we feel that the positioning of home phototherapy may be reconsidered and agreed on. We propose that home ultraviolet B phototherapy should become the primary treatment option for patients who are clinically eligible for phototherapy with ultraviolet $B$ light, and that guidelines should be adapted to reflect this view. In line with the above, in countries where reimbursement of home phototherapy is not routine practice or is even denied, ${ }^{133739}$ reimbursement of home phototherapy should be reconsidered.

In countries where distances to outpatient clinics are large and where home phototherapy is not common practice, treatment with ultraviolet $B$ light may not be available at all for many patients. As a result, patients may receive traditional systemic drugs or expensive biological agents only because the infrastructure to deliver a highly efficacious and cheaper treatment with ultraviolet B light at home is lacking. Such countries should investigate how home phototherapy could be implemented. It is quite likely that introduction of home therapy would achieve cost savings, especially compared with use of biological agents.

In our study, the waiting time for home phototherapy (mean 5.8 weeks) ${ }^{20}$ affected its effectiveness adversely, although this was not directly reflected in patients' satisfaction with the treatment. Although most patients felt that the waiting time was acceptable ${ }^{20}$ we think that home care organisations should be encouraged to reduce the average wait. By doing so, they can easily improve the treatment's effectiveness (number of days with a relevant treatment effect) and will probably increase patient satisfaction with home treatment even further.

\section{Conclusion}

This economic evaluation shows that costs of home ultraviolet B phototherapy for patients with mild to severe psoriasis are not higher than those of ultraviolet B treatment provided in an outpatient department. Moreover, home phototherapy is cost effective. Since both treatment strategies are equally effective and safe, and patients prefer treatment at home, we consider home phototherapy should be the primary treatment option for patients who are clinically eligible for phototherapy with ultraviolet B light. Guidelines should be updated to reflect the results and conclusions of this trial. In countries where home phototherapy is not common practice, implementation of this practice should be investigated. In countries where home phototherapy is available, provision should be improved and home phototherapy should be routinely reimbursed.

We thank all participating patients who made this study possible. We thank Chantal Cornelis (research nurse) for coordinating the contacts with all the patients as well as with the participating hospitals and home care organisations. For the economic analysis, we thank Mart Janssen for his help with bootstrapping, and Wendy J Post for her work on the multilevel models used for extrapolation.

We thank all dermatologists, residents, and other contributing employees of the departments of dermatology of the following hospitals: $U$ MC Utrecht, Hilversum Hospital, Academic Hospital Maastricht, Diakonessen Hospital Utrecht and Zeist, Meander Hospital Amersfoort, Groene Hart Hospital Gouda, AMC Amsterdam, Erasmus MC Rotterdam, VUmc Amsterdam, Gelre Hospital Apeldoorn, Reinier de Graaf Groep Delft and Voorburg, AntoniusMesosGroup Hospitals Utrecht, and Lucas Andreas Hospital Amsterdam. Similarly, we thank all employees of the participating home care organisations Medizorg, Farmadomo, and BEM. Contributors: MBGK, EB, PHAS, VS, and CAFMB-K contributed to the study concept and design. MBGK, HvW, and Chantal Cornelis were involved in the acquisition of data, and HvW and Chantal Cornelis provided administrative, technical, and material support. MBGK, EB, VS, Mart Janssen, and Wendy J Post took part in the analysis and interpretation of the data. MBGKwas the overall study manager and drafted the manuscript. All authors revised the manuscript for important intellectual content and approved the final version for publication. VS is the guarantor. 
Funding: This study was supported by grant 945-02-017 from the Netherlands Organisation for Health Research and Development (ZonMW). ZonMW had no role in the study design; collection, analysis, and interpretation of data; production of the manuscript; or the decision to submit the article for publication. The researchers are independent from the funders.

Competing interests: None declared.

Ethical approval: The institutional review board of the University Medical Center Utrecht approved the study (02/090-0)

1 An appraisal of narrowband (TL-01) UVB phototherapy. British Photodermatology Group Workshop Report (April 1996). Br Dermatol 1997;137:327-30.

2 Ibbotson SH, Bilsland D, Cox NH, Dawe RS, Diffey B, Edwards C, et al. An update and guidance on narrowband ultraviolet $B$ phototherapy: a British Photodermatology Group workshop report. Br J Dermatol 2004;151:283-97.

3 Naldi L, Griffiths CE. Traditional therapies in the management of moderate to severe chronic plaque psoriasis: an assessment of the benefits and risks. Br J Dermatol 2005;152:597-615.

4 Barbagallo J, Spann CT, Tutrone WD, Weinberg JM. Narrowband UVB phototherapy for the treatment of psoriasis: a review and update. Cutis 2001;68:345-7.

5 [Task Force on Psoriasis of the Netherlands Society for Dermatology and Venereology (NVDV). Guideline: photo(chemo)therapy and systemic therapy in severe chronic plaque type psoriasis] [Dutch] 2004. www.cbo.nl/Downloads/376/rl_psoriasis_2005.pdf.

6 Feldman SR, Garton R, Averett W, Balkrishnan R, Vallee J. Strategy to manage the treatment of severe psoriasis: considerations of efficacy, safety and cost. Expert Opin Pharmacother 2003;4:1525-33.

7 Spuls PI, Bossuyt PM, van Everdingen JJ, Witkamp L, Bos JD. The development of practice guidelines for the treatment of severe plaque form psoriasis. Arch Dermatol 1998;134:1591-6.

8 Anstey A. Home UVB phototherapy for psoriasis. BMJ 2009;338:b607.

9 Milstein HJ, Vonderheid EC, Van Scott EJ, Johnson WC. Home ultraviolet phototherapy of early mycosis fungoides: preliminary observations. J Am Acad Dermatol 1982;6:355-62.

10 Resnik KS, Vonderheid EC. Home UV phototherapy of early mycosis fungoides: long-term follow-up observations in thirty-one patients. Am Acad Dermatol 1993;29:73-7.

11 Larko O, Swanbeck G. Home solarium treatment of psoriasis. $\mathrm{Br}$ 」 Dermatol 1979;101:13-6.

12 Jordan WP Jr, Clarke AM, Hale RK. Long-term modified Goeckerman regimen for psoriasis using an ultraviolet $B$ light source in the home. Am Acad Dermatol 1981;4:584-91.

13 Koek MBG, Buskens E, Bruijnzeel-Koomen CAFM, Sigurdsson V. Home ultraviolet B phototherapy for psoriasis: discrepancy between literature, guidelines, general opinions and actual use. Results of a literature review, a web search, and a questionnaire among dermatologists. Br J Dermatol 2006;154:701-11.

14 Van Vloten WA. [Home treatment of psoriasis using ultraviolet-B irradiation] [Dutch]. Ned Tijdschr Geneeskd 1993;137:2525-6.

15 Matto DM, van den Berg-Tap RMC. [Phototherapy at home. More privacy for patients with psoriasis] [Dutch]. Medisch Contact 2003;58:950-2

16 Cameron H, Yule S, Moseley H, Dawe RS, Ferguson J. Taking treatment to the patient: development of a home TL-01 ultraviolet B phototherapy service. Br J Dermatol 2002;147:957-65.

17 Lowe NJ. Home ultraviolet phototherapy. Semin Dermatol 1992;11:284-6.

18 Feldman SR, Clark A, Reboussin DM, Fleischer AB Jr. An assessment of potential problems of home phototherapy treatment of psoriasis. Cutis 1996;58:71-3.

19 Physicians change attitude about home UVB treatment. National Psoriasis Foundation Bulletin 1991;22:15.

20 Koek MBG, Buskens E, van Weelden H, Steegmans PH, BruijnzeelKoomen CAFM, Sigurdsson V. Home versus outpatient ultraviolet B phototherapy for mild to severe psoriasis: pragmatic multicentre randomised controlled non-inferiority trial (PLUTO study). BMJ 2009;338:b1542.

21 Koek MBG, Buskens E, Steegmans PHA, van Weelden H, BruijnzeelKoomen CAFM, Sigurdsson V. UVB phototherapy in an outpatient setting or at home: a pragmatic randomised single-blind tria designed to settle the discussion. The PLUTO study. BMC Med Res Methodol 2006;6:39.

22 Van Roijen L, Essink-Bot ML, Koopmanschap MA, Bonsel G, Rutten FF. Labor and health status in economic evaluation of health care. The health and labor questionnaire. Int J Technol Assess Health Care 1996;12:405-15

23 Oostenbrink JB, Bouwmans CAM, Koopmanschap MA, Rutten FFH. [Manual for costing: methods and standard costs for economic evaluations in healthcare] [Dutch]. College voor Zorgverzekeringen, 2004.

24 [Statistics Netherlands (CBS)]. Zorgrekeningen; kerncijfers en uitgaven conform diverse classificaties. [Dutch] 2006. http:// statline.cbs.nl/StatWeb/publication/? $\mathrm{DM}=\mathrm{SLNL} \& \mathrm{PA}=37494 \& \mathrm{D} 1=14-15,18 \& \mathrm{D} 2=(\mathrm{l}-2)-\mathrm{l} \& \mathrm{VW}=\mathrm{T}$

25 [Dutch Health Care Insurance Board (CVZ). Medication guide 2003] [Dutch]. Bohn Stafleu van Loghum, 2003.

26 [Royal Dutch Association for the Advancement of Pharmacy (KNMP). The price- and the reimbursement system for medicines and its history] [Dutch]. 2006. www.knmp.nl/leden/pers/extra.asp? $\mathrm{mID}=4776$ \& rID=1405\&inhoud=1.

27 Jacob-Tacken KH, Koopmanschap MA, Meerding W], Severens JL. Correcting for compensating mechanisms related to productivity costs in economic evaluations of health care programmes. Health Econ 2005;14:435-43.

28 Severens JL, Laheij RJ, Jansen JB, Van der Lisdonk EH, Verbeek AL. Estimating the cost of lost productivity in dyspepsia. Alimen Pharmacol Ther 1998;12:919-23.

29 Fredriksson T, Pettersson U. Severe psoriasis—oral therapy with a new retinoid. Dermatologica 1978;157:238-44.

30 Feldman SR, Fleischer AB Jr, Reboussin DM, Rapp SR, Exum ML, Clark AR, et al. The self-administered psoriasis area and severity index is valid and reliable. J Invest Dermatol 1996;106:183-6.

31 Fleischer AB Jr, Rapp SR, Reboussin DM, Vanarthos JC, Feldman SR. Patient measurement of psoriasis disease severity with a structured instrument. J Invest Dermatol 1994;102:967-9.

32 Fleischer AB Jr, Feldman SR, Dekle CL. The SAPASI is valid and responsive to psoriasis disease severity changes in a multi-center clinical trial. J Dermatol 1999;26:210-5.

33 The EuroQol Group. EuroQol* - a new facility for the measurement of health-related quality of life. Health Policy 1990;16:199-208.

34 Brazier J, Roberts J, Deverill M. The estimation of a preference-based measure of health from the SF-36. J Health Econ 2002;21:271-92.

35 Brazier J, Roberts J, Tsuchiya A, Busschbach J. A comparison of the EQ-5D and SF-6D across seven patient groups. Health Econ 2004;13:873-84.

36 Fenwick E, O'Brien BJ, Briggs A. Cost-effectiveness acceptability curves-facts, fallacies and frequently asked questions. Health Econ 2004;13:405-15.

37 Yelverton CB, Kulkarni AS, Balkrishnan R, Feldman SR. Home ultraviolet B phototherapy: a cost-effective option for severe psoriasis. Manag Care Interface 2006;19:33-9.

38 Abel EA. Considerations in the use of home ultraviolet radiation therapy for psoriasis. Cutis 1985;35:127-8, 130.

39 Simpson GL, Yelverton CB, Rittenberg S, Feldman SR. Do utilization management controls for phototherapy increase the prescription of biologics? I Dermatolog Treat 2006;17:359-61.

40 Yelverton CB, Yentzer BA, Clark A, Pearce DJ, Balkrishnan R, Camacho FT, et al. Home narrowband UV-B phototherapy in combination with low-dose acitretin in patients with moderate to severe psoriasis. Arch Dermatol 2008;144:1224-5.

41 Yentzer BA, Yelverton CB, Pearce DJ, Camacho FT, Makhzoumi Z, Clark $A$, et al. Adherence to acitretin and home narrowband ultraviolet B phototherapy in patients with psoriasis. J Am Acad Dermatol 2008;59:577-81.

42 De Rie MA, de Hoop D, Jonsson L, Bakkers El, Sorensen M. Pharmacoeconomic evaluation of calcipotriol (Daivonex/Dovonex) and UVB phototherapy in the treatment of psoriasis: a Markov model for The Netherlands. Dermatology 2001;202:38-43.

43 [National Health Tariffs Authority (CTG). Online price lists, 2006] [Dutch]. 2006. http://ctg.bit-ic.nl/Nzatarieven/top.do.

44 Zorg en zekerheid. [Online list of tariffs and reimbursements] [Dutch]. 2008. www.zorgenzekerheid.nl/xmsp/xms_itm_p.download_file? p_itm_id=1614.

Accepted: 5 January 2010 